\title{
Bearing capacity of strip footings on unsaturated soils by the slip line theory
}

\author{
Thanh Vo ${ }^{1, a}$ and Adrian Russell ${ }^{1}$ \\ ${ }^{1}$ Centre for Infrastructure Engineering and Safety, School of Civil and Environmental Engineering, The University of New South Wales, \\ Sydney, NSW, Australia
}

\begin{abstract}
The bearing capacity of strip footings on unsaturated soils is studied using slip line theory. The suction profiles considered are non-uniform with depth and correspond to vertical flow of water by infiltration or evaporation. The slip line theory assumes a plastic equilibrium state of a Mohr-Coulomb soil in which suction influences are included using the effective stress concept. This paper shows that the influence of a non-uniform suction profile on bearing capacity is significant. When the contribution of suction to the effective stress can be approximated as a function that varies linearly with depth, the effects of suction on bearing capacity can be represented in dimensionless form in separate charts for smooth and rough footings. Using the charts the bearing capacity can be determined for any combination of friction angle, footing width, surcharge, soil unit weight and linear profiles of cohesion and the contribution of suction to the effective stress.
\end{abstract}

\section{Introduction}

Foundations are ubiquitous to geotechnical engineering. Current design tools for estimating ultimate bearing capacity are only applicable when foundation soils are fully saturated or dry. Shallow foundations, however, operate in the upper fewer meters of the ground, often above the water table where soils are variably saturated and may never become fully saturated. As a result the true margins of safety cannot be known for shallow foundations on unsaturated soils using existing tools.

The significant influence that suction can have on bearing capacity has been recognised in the literature. Meyerhof [1] and Vesic [2] recommended suction be treated as an apparent cohesion and shallow foundations be designed based on the highest possible ground water table. Vesic [2] suggested that when the distance between the ground water table and the base of the foundation is less than the foundation width then the soil unit weight should be modified to account for suction above the water level. More recently Oloo et al. [3] and Costa et al. [4] incorporated suction into Terzaghi-type bearing capacity calculations by treating it as an apparent cohesion that was constant with depth. A suction related term, in addition to cohesion, contributed to bearing capacity when scaled by the bearing capacity factor $N_{\mathrm{c}}$. $\mathrm{Xu}$ [5] observed in experiments a suction dependant increase in bearing capacity in unsaturated expansive soils. Jahanandish et al. [6] accounted for this increase in an analysis using zero extension line theory. Again suction was treated as an apparent cohesion constant with depth that contributed to bearing capacity through $N_{\mathrm{c}}$. It is recognised that suction and apparent cohesion have similar but separate effects on stress equilibrium.

Never before has the effect of a non-uniform suction profile with depth been considered in a bearing capacity analysis of frictional soil. Suction may be highest at very shallow depths where soil interacts with the environment and evaporation may occur. But suction may decay with depth and vanish all together the ground water table. This non-uniformity introduces uncertainties in to how suction may influence bearing capacity and to what extent it may be relied upon during the service life of the footing.

The slip line theory [7-9] is widely used to calculate the ultimate bearing capacity of a strip footing. It involves assuming limit stresses are reached at every point in the soil foundation while an equilibrium stress state is maintained. This avoids use of arbitrarily assumed failure mechanisms. The aim of this paper is to study the influence of steady state suction profiles, set up through evaporation or infiltration, on the bearing capacity of a surface strip footing using the slip line theory.

\section{Slip line governing equations}

\subsection{Effective stress and failure criterion}

The governing equations are formulated based on the effective stress concept for unsaturated soils [10]. The effective stress $\left(\sigma^{\prime}\right)$ is defined as:

$$
\sigma^{\prime}=\sigma-u_{\mathrm{a}}+\chi\left(u_{\mathrm{a}}-u_{\mathrm{w}}\right)
$$

\footnotetext{
a Corresponding author: thanh.vo@unsw.edu.au
} 
where $\sigma \equiv$ total stress, $u_{\mathrm{a}} \equiv$ pore air pressure, $u_{\mathrm{w}} \equiv$ pore water pressure and $\chi \equiv$ effective stress parameter. Eq. 1 can be rewritten as:

$$
\sigma^{\prime}=\sigma_{\mathrm{n}}+\chi s
$$

where $s=u_{\mathrm{a}}-u_{\mathrm{w}}$ and $\sigma_{\mathrm{n}}=\sigma-u_{\mathrm{a}} \equiv$ net stress, that is the total stress in excess of pore air pressure. When pore air pressure is equal to atmospheric pressure and is taken as the pressure datum, the net stress and total stress become the same. The subscript $\mathrm{n}$ may then be removed to simplify notation $\left(\sigma^{\prime}=\sigma+\chi s\right)$.

The expression for $\chi$ when the hydraulic state of the soil is located on the main drying or the main wetting branch of the soil-water characteristic curve is (Khalili and Khabbaz, [11]):

$$
\begin{gathered}
\chi=1, \mathrm{~s} \leq s_{\mathrm{e}} \\
\chi=\left(s / s_{\mathrm{e}}\right)^{-0.55}, s>s_{\mathrm{e}}
\end{gathered}
$$

where $s_{\mathrm{e}} \equiv$ suction value separating saturated from unsaturated states $\left(s_{\mathrm{e}}=s_{\mathrm{ae}} \equiv\right.$ air entry suction and applies when the hydraulic state is on the main drying branch, $s_{\mathrm{e}}=s_{\mathrm{ex}} \equiv$ air expulsion suction and applies when the hydraulic state is on the main wetting branch). Eq. 3 is appealing because it is simple and has been validated extensively using experimental data.

The Mohr-Coulomb failure criterion may be written as:

$$
\begin{gathered}
\sigma_{\mathrm{xx}}=\left[\left(1+\sin \varphi^{\prime} \cos 2 \theta\right) \sigma_{\mathrm{m}}{ }^{\prime}-c^{\prime} \cot \varphi\right]-\chi s \\
\sigma_{\mathrm{yy}}=\left[\left(1-\sin \varphi^{\prime} \cos 2 \theta\right) \sigma_{\mathrm{m}}{ }^{\prime}-c^{\prime} \cot \varphi^{\prime}\right]-\chi s \\
\sigma_{\mathrm{xy}}=\sin \varphi^{\prime} \sin 2 \theta \sigma_{\mathrm{m}}{ }^{\prime}
\end{gathered}
$$

where $\sigma_{\mathrm{xx}}, \sigma_{\mathrm{yy}} \equiv$ normal stresses in the $x$ and $y$ directions, respectively, $\sigma_{\mathrm{m}}{ }^{\prime} \equiv$ effective mean stress, $\sigma_{\mathrm{xy}} \equiv$ shear stress, $c^{\prime} \equiv$ soil cohesion, $\varphi^{\prime} \equiv$ soil friction angle and $\theta \equiv$ angle between the vertical axis and the major principal stress direction. Here $\varphi^{\prime}$ is taken to be a material constant for simplicity (ignoring the slight dependence it may have on soil density, confining pressure, loading history and suction). $c^{\prime}$ and $\chi s$ will be set to be zero, constant or vary with depth as will be clearly indicated in the paper.

\subsection{Stress equations}

The coordinates system used by Sokolovski [9] is adopted in this paper where $x \equiv$ vertical direction and $y \equiv$ horizontal direction (Figure 1). The stress components in Eq. 4 can be differentiated with respect to distance and substituted into the static equilibrium equation. After some simplifications two families of stress characteristic curves are obtained: the $\eta$ family defined by Eq. 5 and the $\xi$ family defined by Eq. 6:

$$
\begin{aligned}
& \mathrm{d} y=\tan (\theta+\mu) \mathrm{d} x \\
& \mathrm{~d} \sigma_{\mathrm{m}}{ }^{\prime}+2 \tan \varphi^{\prime} \sigma_{\mathrm{m}}{ }^{\prime} \mathrm{d} \theta=\mathrm{C}_{1} \\
& \mathrm{~d} y=\tan (\theta-\mu) \mathrm{d} x \\
& \mathrm{~d} \sigma_{\mathrm{m}}{ }^{\prime}-2 \tan \varphi^{\prime} \sigma_{\mathrm{m}}{ }^{\prime} \mathrm{d} \theta=\mathrm{C}_{2}
\end{aligned}
$$

where $\quad \mathrm{C}_{1}=\left[\gamma_{\mathrm{t}}+\partial\left(c^{\prime} \cot \varphi^{\prime}+\chi s\right) / \partial x\right]\left(\mathrm{d} x-\tan \varphi^{\prime} \mathrm{d} y\right) \quad$ and $\mathrm{C}_{2}=\left[\gamma_{\mathrm{t}}+\partial\left(c^{\prime} \cot \varphi^{\prime}+\chi s\right) / \partial x\right]\left(\mathrm{d} x+\tan \varphi^{\prime} \mathrm{d} y\right), \gamma_{\mathrm{t}} \equiv$ soil unit weight and $\mu=\pi / 4-\varphi^{\prime} / 2$. To arrive at Eqs. 5 and 6 , it has been assumed cohesion and suction do not change in the horizontal direction. The term $\partial\left(c^{\prime} \cot \varphi^{\prime}+\chi s\right) / \partial x$ in Eqs. 5 and 6 indicates that $c^{\prime} \cot \varphi^{\prime}$ and $\chi s$ have similar but separate effects on stress equilibrium.

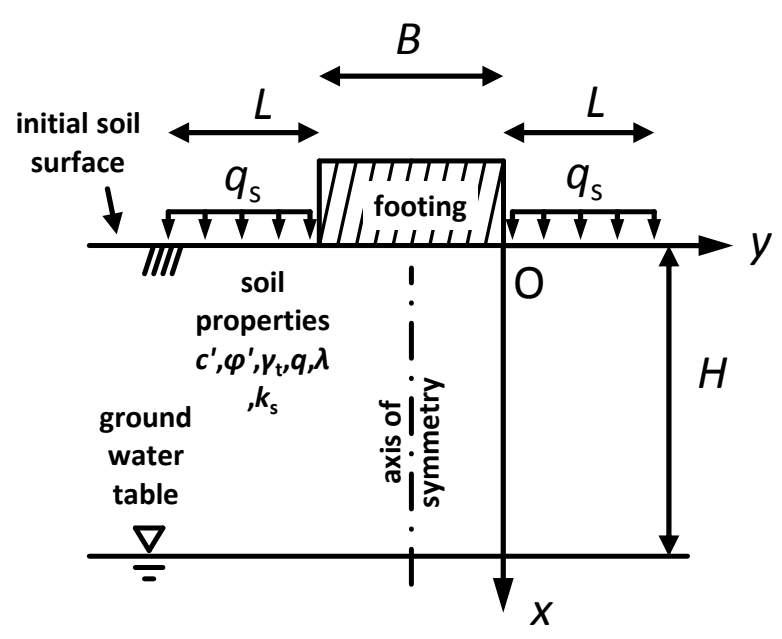

Figure 1. Problem geometry and parameters

\subsection{Suction function and water pressure profile}

A steady state suction function was derived by $\mathrm{Lu}$ and Griffiths [12] by combining Darcy's law [13, 14] for vertical unsaturated flow and Gardner's permeability model [15]. A modified version of this function is used here. The modification ensures that a saturated condition is achieved when $s \leq s_{\mathrm{e}}$, contrary to it being achieved for $s=0$ in the original formulation. The permeability model used is:

$$
\begin{gathered}
k=k_{\mathrm{s}}, s \leq s_{\mathrm{e}} \\
k=k_{\mathrm{s}} \exp \left[\mathrm{A}_{1}\left(1-s / s_{\mathrm{e}}\right)\right], s>s_{\mathrm{e}}
\end{gathered}
$$

where $k \equiv$ unsaturated hydraulic conductivity, $k_{\mathrm{s}} \equiv$ saturated hydraulic conductivity and $\mathrm{A}_{1} \equiv$ a fitting constant $\left(\mathrm{A}_{1}=1\right.$ is adopted in this paper). Eq. 7 is combined with Darcy's law for vertical unsaturated flow to obtain:

$$
\begin{aligned}
& s=\gamma_{\mathrm{w}}, s \leq s_{\mathrm{e}} \\
& s=S_{\mathrm{e}}-\left(s_{\mathrm{e}} / \mathrm{A}_{1}\right) \ln \left\{\left(1+q / k_{\mathrm{s}}\right) \exp \left[\mathrm{A}_{1}\left(1-\gamma_{\mathrm{w}} \bar{x} / s_{\mathrm{e}}\right)\right]-q / k_{\mathrm{s}}\right\}, s>s_{\mathrm{e}}
\end{aligned}
$$

in which $\bar{x}$ is the height above a horizontal ground water table (Figure 2). The water table is at a distance $H$ below the soil surface and $\bar{x}=H-x$.

As Eq. 8 is relatively simple with physically intuitive parameters it is adopted in this paper to compute steady state suction profiles typical of sands and silts. The influence of the suction profiles on stress equilibrium can 
be found by calculating $\partial\left(c^{\prime} \cot \varphi^{\prime}+\chi s\right) / \partial x$ in Eq. 6. For constant $c^{\prime}$ it is found that $\partial\left(c^{\prime} \cot \varphi^{\prime}+\chi s\right) / \partial x=$

$$
\begin{aligned}
& \partial(\chi s) / \partial x=-\gamma_{\mathrm{w}}, \quad s \leq s_{\mathrm{e}} \text { where } x \geq H-s_{\mathrm{e}} / \gamma_{\mathrm{w}} \\
& \partial(\chi s) / \partial x=\mathrm{C}_{3} / \mathrm{C}_{4}, s>s_{\mathrm{e}} \text { where } x<H-s_{\mathrm{e}} / \gamma_{\mathrm{w}}
\end{aligned}
$$

with $\mathrm{C}_{3}=-0.45\left(1+q / k_{\mathrm{s}}\right) \gamma_{\mathrm{w}} \mathrm{A}_{2}$ and $\mathrm{C}_{4}=\left[\mathrm{A}_{2}\left(1+q / k_{\mathrm{s}}\right)-q / k_{\mathrm{s}}\right]\left\{1-\left(1 / \mathrm{A}_{1}\right) \ln \left[\mathrm{A}_{2}\left(1+q / k_{\mathrm{s}}\right)-q / k_{\mathrm{s}}\right]\right\}^{0.55}$ in which $\mathrm{A}_{2}=\exp \left\{\mathrm{A}_{1}\left[1-\gamma_{\mathrm{w}}(H-x) / s_{\mathrm{e}}\right]\right\}$.

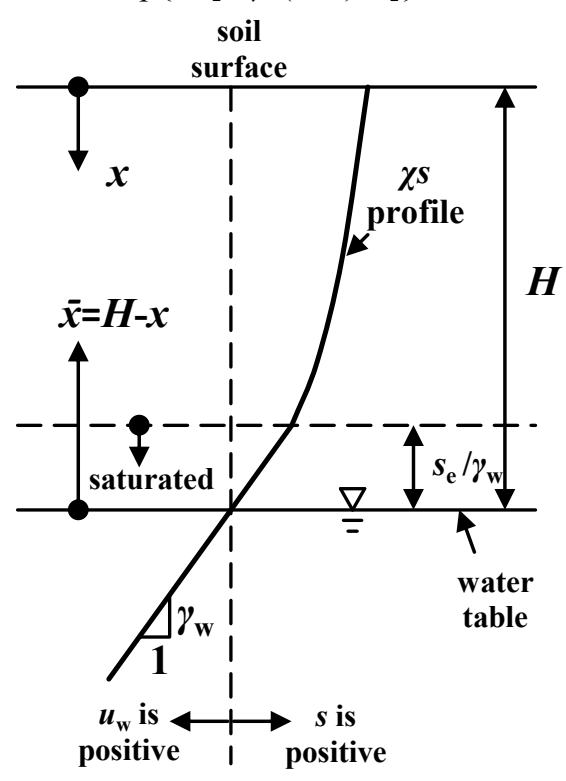

Figure 2. A typical $\chi s$ profile in soil

\section{The strip footing problem}

\subsection{Problem definition}

A typical strip footing is shown in Figure 1. Only the case when the footing load is larger than the surcharge load is considered here which Sokolovski [9] referred to as the heaving problem. The suction profile in the unsaturated region is assumed to be at a steady state. The water pressure in the saturated region is assumed hydrostatic and the effect of water exchange with the unsaturated region is assumed negligible. The unsaturated flow occurs in the vertical direction only and may be either an evaporative (positive) flow for which the soil's hydraulic state is assumed to always be on the main drying curve or infiltrative (negative) flow for which the hydraulic state is assumed to always be on the main wetting curve. The effects of soil deformation and changes to soil structure on $s_{\mathrm{e}}$ are assumed negligible. Because the problem is symmetric about a vertical line (shown in Figure 1) it is possible to work with one-half of the geometry. The right-half of the geometry is referred to in this paper.

\subsection{Boundary conditions}

At the soil surface away from the footing contact interface the two variables $\sigma_{\mathrm{m}}{ }^{\prime}$ and $\theta$ can be written as:

$$
\begin{gathered}
\sigma_{\mathrm{m}}{ }^{\prime}=\left(q_{\mathrm{s}}+\chi s+c^{\prime} \cot \varphi^{\prime}\right) /\left(1+\sin \varphi^{\prime} \cos 2 \theta\right) \\
\theta=\pi / 2
\end{gathered}
$$

The singular point $\mathrm{O}$ (shown in Figure 1) is treated as a characteristic curve in the limit extending from point $\mathrm{O} 1$ on the soil surface to point $\mathrm{O} 2$ at the edge of the footing. At a point $\mathrm{M}$ on this curve the variable $\sigma_{\mathrm{m}}{ }^{\prime}$ is evaluated as:

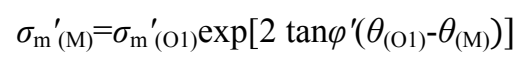

At the soil-footing interface:

$$
\theta=-\Delta / 2-\delta^{\prime} / 2
$$

where $\Delta=\sin ^{-1}\left(\sin \left(\delta^{\prime} / \sin \varphi^{\prime}\right)\right)$. For rough footings $\delta^{\prime}=\varphi^{\prime}$, $\Delta=\pi / 2$ and $\theta=-\pi / 4-\varphi^{\prime} / 2$. For smooth footings $\delta^{\prime}=0, \Delta=0$ and $\theta=0$. For $0<\delta^{\prime}<\varphi^{\prime}, \theta$ depends on the adopted $\delta^{\prime}$. Another boundary condition can be derived for the soilfooting interface from the coordinates system (Figure 1). For a smooth footing:

$$
x=0
$$

along the entire interface. For $0<\delta^{\prime} \leq \varphi^{\prime}$, Eq. 14 only applies to part of the footing width $[16,17]$.

It has been widely discussed [18] that plastic yielding (according to the assumed Mohr-Coulomb failure criterion) cannot occur at the axis of symmetry (Figure 1) for $0<\delta^{\prime} \leq \varphi^{\prime}$. Different approaches have been adopted to circumvent the problem of not having zero shear stress on the axis of symmetry for $0<\delta^{\prime} \leq \varphi^{\prime}$. The approach adopted here is similar to Davis and Booker [16] and Martin [17] in assuming that a soil wedge is trapped between the plastic zone and the footing. A stress field is searched so that $\theta=0$ is satisfied on the axis of symmetry. The exact shape and extent of the wedge is governed by the problem parameters. It extends to the edge of the footing or to a certain point on the footing.

\subsection{Solution procedures}

A standard finite difference scheme is used to discretise the governing equations (Eq. 5 and Eq. 6) in the same way as Sokolovski [9]. Details of numerical implementation for dry soils can be found in references $[9,17]$. For unsaturated soils the variables $\left(\sigma_{\mathrm{m}}{ }^{\prime}, \theta, x, y\right)$ at each grid point of the finite difference mesh need to be updated with Eq. 9 until convergence. It is also necessary to adopt an adaptive subdivision strategy to control the level of mesh distortion in the fan zone. An adaptive subdivision strategy similar to Martin [17] is used here.

\section{Results of slip line analyses}

Results are presented in total normal stresses (denoted $\left.\sigma_{\mathrm{xx}_{\text {_interface }}}\right)$ on a soil-footing interface. For simplicity a soil unit weight $\gamma_{\mathrm{t}}=17 \mathrm{kN} / \mathrm{m}^{3}$ is adopted. It will be shown later that $\gamma_{\mathrm{t}}$ has a significant effect on bearing capacity.

Typical parameters of sands $\left(\varphi^{\prime}=40^{\circ}, 45^{\circ}\right)$ and silts $\left(\varphi^{\prime}=25^{\circ}, 30^{\circ}\right)$ whilst unsaturated are used to compute the 
$\chi S$ profiles for evaporation $\left(q=1.15 \times 10^{-8} \mathrm{~m} / \mathrm{s}\right)$ and infiltration $\left(q=-3.14 \times 10^{-8} \mathrm{~m} / \mathrm{s}\right)$, as listed in Table 1 .

Table 1. Parameters adopted in analyses.

\begin{tabular}{|c|c|c|c|}
\hline $\boldsymbol{\varphi}^{\prime}\left(^{\circ}\right)$ & $\boldsymbol{s}_{\mathbf{e}}$ (kPa) & $\boldsymbol{k}_{\mathbf{s}}(\mathbf{m} / \mathbf{s})$ & $\boldsymbol{q}(\mathbf{m} / \mathbf{s})$ \\
\hline 25 & 15 (infiltration) & $1 \times 10^{-7}$ & $-3.14 \times 10^{-8}$ \\
\hline 25 & 75 (evaporation) & $1 \times 10^{-7}$ & $1.15 \times 10^{-8}$ \\
\hline 30 & 15 (infiltration) & $1 \times 10^{-7}$ & $-3.14 \times 10^{-8}$ \\
\hline 30 & 75 (evaporation) & $1 \times 10^{-7}$ & $1.15 \times 10^{-8}$ \\
\hline 40 & 2 (infiltration) & $3 \times 10^{-4}$ & $-3.14 \times 10^{-8}$ \\
\hline 40 & 10 (evaporation) & $3 \times 10^{-4}$ & $1.15 \times 10^{-8}$ \\
\hline 45 & 2 (infiltration) & $3 \times 10^{-4}$ & $-3.14 \times 10^{-8}$ \\
\hline 45 & 10 (evaporation) & $3 \times 10^{-4}$ & $1.15 \times 10^{-8}$ \\
\hline
\end{tabular}

For $H=10 \mathrm{~m}$ the corresponding $\chi s$ profiles computed using Eqs. 3 and 8 are shown in Figure $3 a$ for silt and Figure $3 \mathrm{~b}$ for sand. They show that the $\chi s$ profiles may be approximated by linear functions.

\subsection{Smooth and rough footings}

Figure $4 \mathrm{a}$ and Figure $4 \mathrm{~b}$ show distributions of $\sigma_{\mathrm{xx} \text { interface }}$ for a two meters wide smooth strip footing. $H=10 \mathrm{~m}$ is used. Figure $5 \mathrm{a}$ and Figure $5 \mathrm{~b}$ show distributions of $\sigma_{\text {xx_interface }}$ for a rough footing, $B=2 \mathrm{~m}$ and $H=10 \mathrm{~m}$. $\sigma_{\mathrm{xx} \text { interface }}$ for the rough footing is higher than that for the smooth footing.

The results show that $\sigma_{\mathrm{xx} \text { interface, }}$ and thus the bearing capacity, is strongly linked to whether the sand or silt is undergoing evaporation or infiltration. This is due to a significant difference in the $\chi s$ profiles (Figure 3 ).

\subsection{Influence of footing width}

The influence of $B$ is investigated by repeating the analyses in section 4.1 for a typical sand $\left(\varphi^{\prime}=40^{\circ}\right)$ and silt $\left(\varphi^{\prime}=25^{\circ}\right)$ in steady state evaporation. $B=6 \mathrm{~m}$ and $B=18 \mathrm{~m}$ are considered along with $B=2 \mathrm{~m}$. The results are shown in Figure 6.

Figure 6 shows that the results for a particular unsaturated soil with a certain $\varphi^{\prime}$ value but for different footing widths do not coincide when presented in $\sigma_{\mathrm{xx} \text { interface }} /\left(\gamma_{\mathrm{t}} B\right) \sim y / B$, contrary to what is observed for dry soils [19].
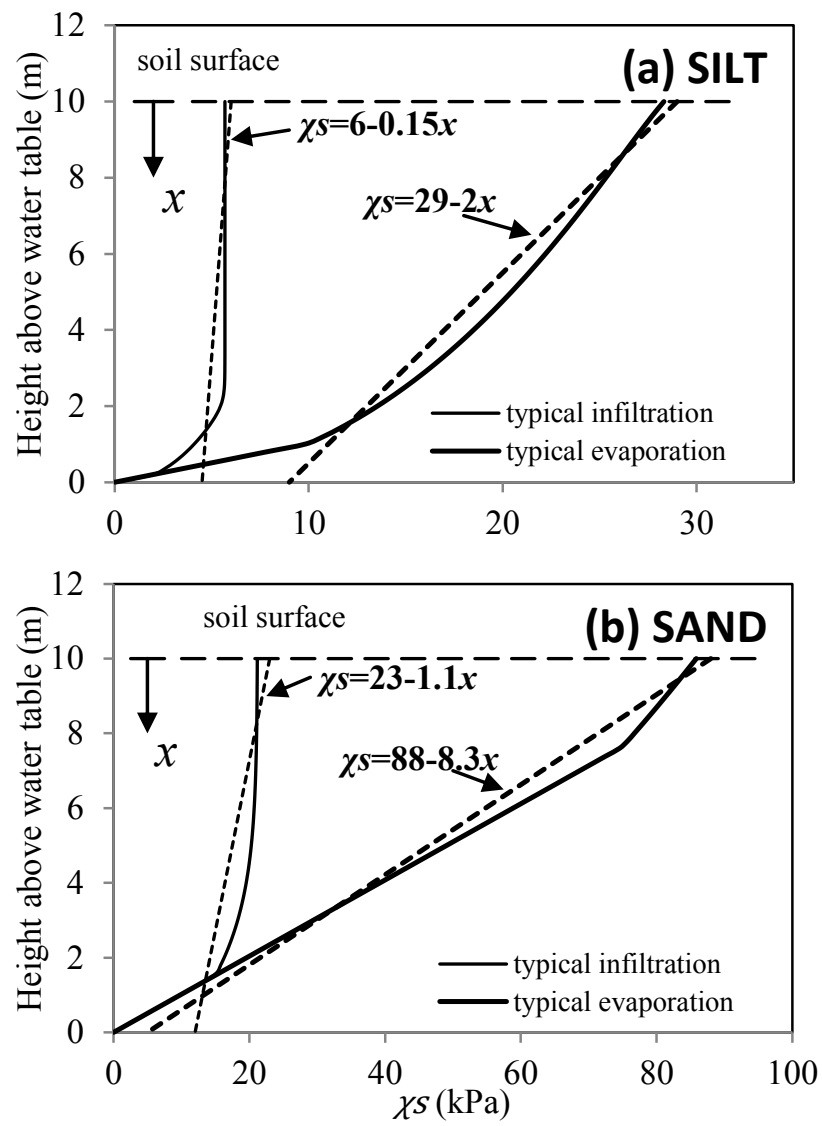

Figure 3. Typical infiltration and evaporation in sand and silt

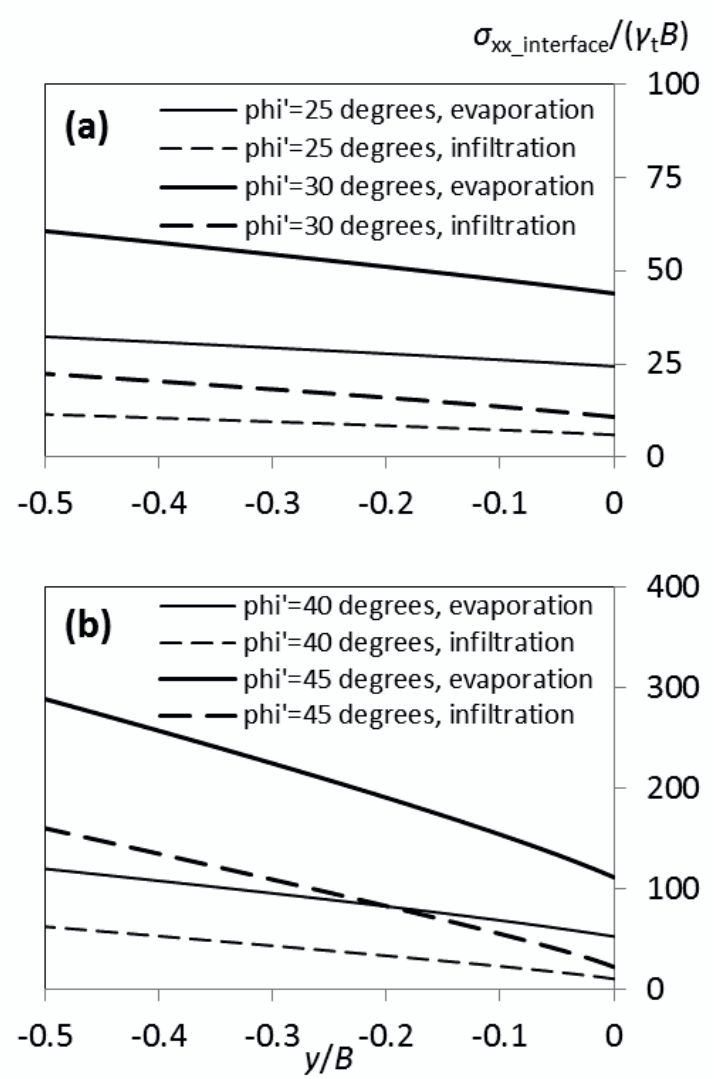

Figure 4. Total normal stress at a smooth soil-footing interface 

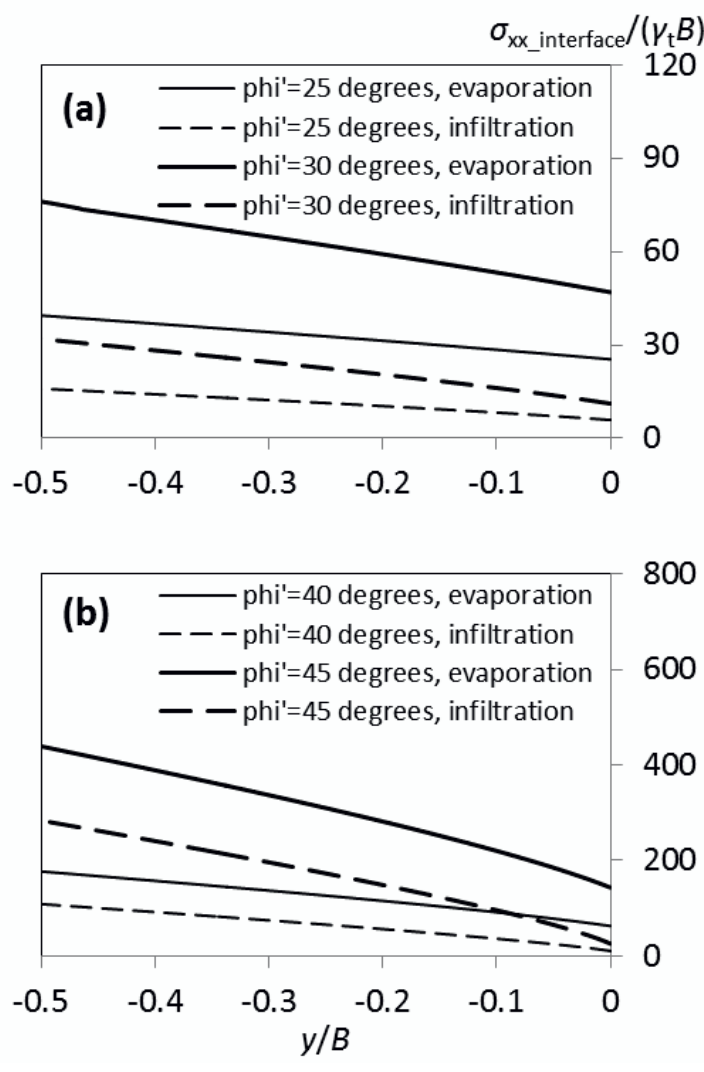

Figure 5. Total normal stress at a rough soil-footing interface
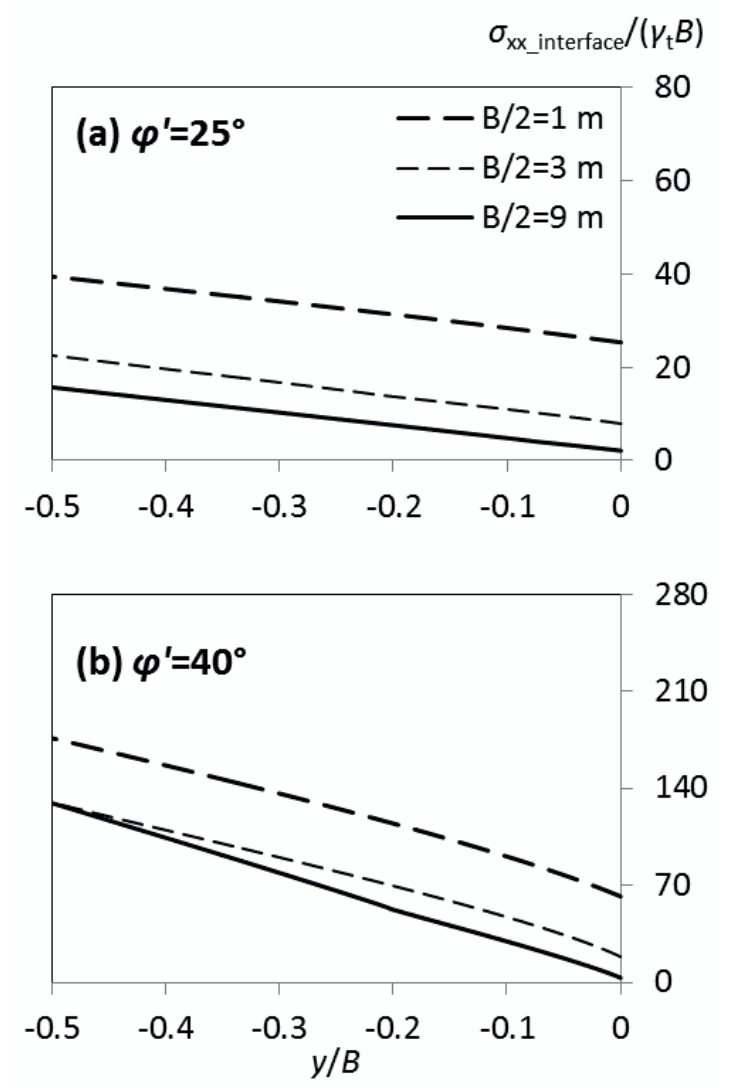

Figure 6. Influence of $B$ on $\sigma_{\mathrm{xx} \text { interface }} /\left(\gamma_{\mathrm{t}} B\right)$ at a soil-footing interface
The results for unsaturated silt and evaporation are most divergent. The amount of divergence depends on $\chi s$ and its variation with depth, which is scale dependent. To understand this it is helpful to refer to the results of Davis and Booker [20] who studied the influence of a linearly varying cohesion profile on the bearing capacity of clays, as cohesion has a similar influence to $\chi s / \cot \varphi^{\prime}$. Davis and Booker [20] identified $c_{0}{ }^{\prime} /\left(K_{\mathrm{c}} B\right)$ (where $c_{0}{ }^{\prime} \equiv$ soil cohesion at soil surface and $K_{\mathrm{c}} \equiv$ rate of cohesion increase with depth) to be the variable controlling the bearing capacity. This can be shown readily by formulating the governing equations in non-dimensional form [9, 17]. It can be inferred from this that the divergence of the results in Figure 6 is due to $\chi s$ at the soil surface and $\partial(\chi s) / \partial x$ being different for each case. An alternate presentation is needed to see coincidence of results which is discussed below.

\section{Incorporating a suction profile into bearing capacity calculation}

The analyses completed above involve $\chi s$ profiles which are nonlinear with depth. Here it is shown how linear approximations to those profiles may be incorporated into a bearing capacity calculation.

Consider first dry soils in which $\varphi^{\prime}$ and $\gamma_{\mathrm{t}}$ are constant but have a cohesion profile that varies linearly with depth according to $c^{\prime}=c_{0}{ }^{\prime}+K_{\mathrm{c}} x$. It was shown in Martin [17] that the dimensionless ratio:

$$
V=q_{\mathrm{u}} /\left(c_{0}{ }^{\prime}+q_{\mathrm{s}} \tan \varphi^{\prime}\right)
$$

is dependent on the dimensionless factor:

$$
F=\left(K_{\mathrm{c}} B+\gamma_{\mathrm{t}} B \tan \varphi^{\prime}\right) /\left(c_{0}{ }^{\prime}+q_{\mathrm{s}} \tan \varphi^{\prime}\right)
$$

and the values of $\varphi^{\prime}$. To incorporate suction influences it is recognised that $c^{\prime} \cot \varphi^{\prime}$ and $\chi s$ have similar (and independent) effects on the governing equations. If a linear suction profile exists defined by:

$$
\chi s=(\chi s)_{0}+K_{\chi s} x
$$

where $(\chi s)_{0}$ is the value of $\chi s$ at the ground surface and $K_{\chi s}=\partial(\chi s) \partial x$ is a constant, along with a linearly varying cohesion profile with depth, and constant $\varphi^{\prime}$ and $\gamma_{t}$, then a more general form of the ratio $V$ becomes:

$$
V=q_{\mathrm{u}} /\left(c_{0}{ }^{\prime}+(\chi s)_{0} \tan \varphi^{\prime}+q_{\mathrm{s}} \tan \varphi^{\prime}\right)
$$

and this must be dependent on a modified $F$ :

$$
F=\left[\left(K_{\mathrm{c}}+K_{\chi \mathrm{s}} \tan \varphi^{\prime}+\gamma_{\mathrm{t}} \tan \varphi^{\prime}\right) B\right] /\left(c_{0}{ }^{\prime}+(\chi s)_{0} \tan \varphi^{\prime}+q_{\mathrm{s}} \tan \varphi^{\prime}\right)
$$

along with $\varphi^{\prime}$. The parameters $(\chi s)_{0}$ and $K_{\chi \mathrm{s}}$ may be estimated using linear fits to the suction profiles arrived at using Eqs. 3 and 8 as shown in Figure 3. The errors associated with using a linear approximation for the $\chi s$ profiles rather than the curved profiles are small.

The unique relationships between $V$ and $F$ for different $\varphi^{\prime}$ values are shown graphically in Figure $7 \mathrm{a}$ and Figure $7 \mathrm{~b}$ for smooth and rough footings, respectively. 
This figure can be used to determine $q_{\mathrm{u}}$ for any combination of $\varphi^{\prime}, c_{0}{ }^{\prime}, K_{\mathrm{c}}, B,(\chi s)_{0}, K_{\chi \mathrm{s}}, q_{\mathrm{s}}$ and $\gamma_{\mathrm{t}}$.

In Figure 7, as $F \rightarrow 0, \quad V \rightarrow N_{\mathrm{c}}$ and as $\mathrm{F} \rightarrow \infty$, $V \rightarrow\left[N_{\gamma} /\left(2 \tan \varphi^{\prime}\right)\right] F$. These limiting conditions are represented by the straight dash lines.

\section{Conclusion}

The bearing capacity of a shallow strip footing in unsaturated soils has been investigated by the slip line method. The stress field governing equations are formulated based on the effective stress concept for unsaturated soils. Bearing capacity analyses are carried out for typical sands and silts in steady state evaporation and infiltration.. When the contribution of suction to effective stress varies linearly with depth the influence of suction can be captured by plotting results in dimensionless form. These plots are a useful tool for practitioners to estimate bearing capacity.
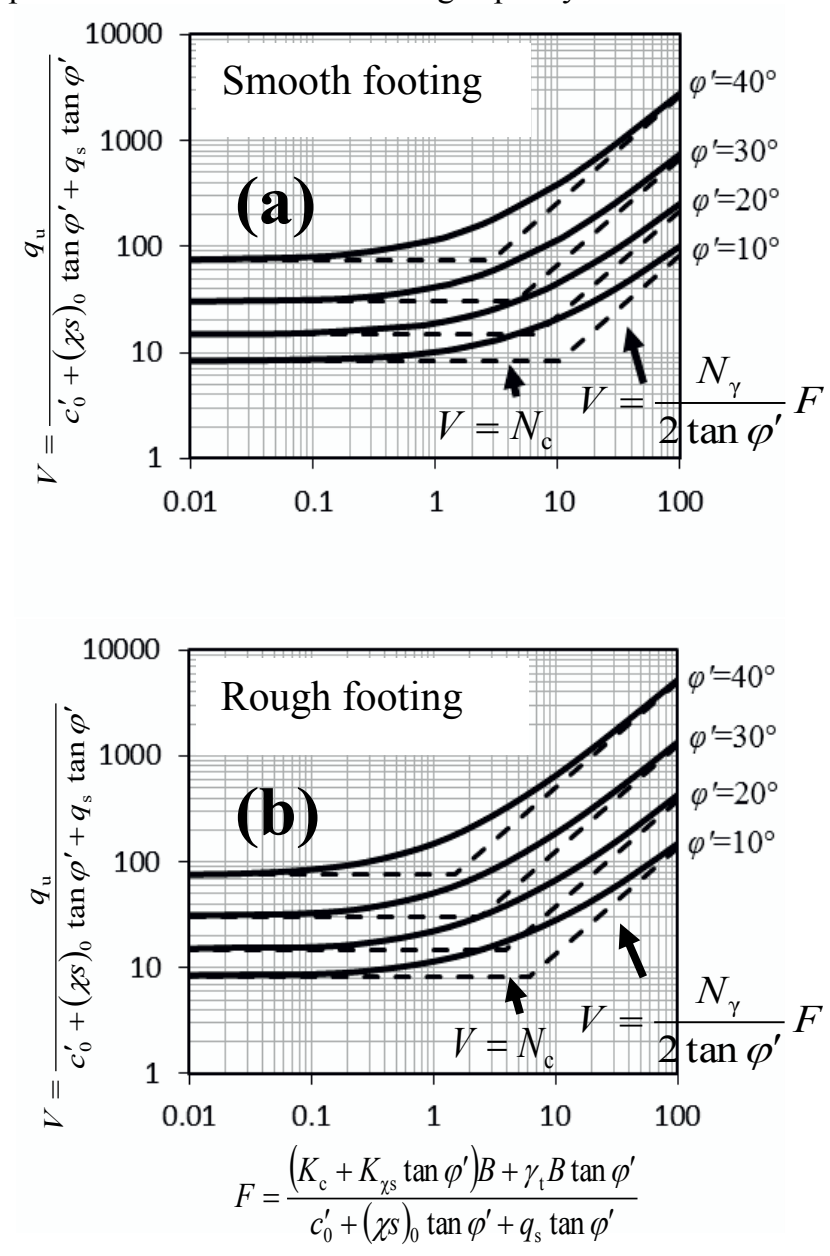

Figure 7. The unique relationship between $V$ and $F$ for different $\varphi^{\prime}$ values

\section{References}

[1] Meyerhof GG. Influence of roughness of base and ground water conditions on the ultimate bearing capacity of foundations. Géotechnique. 1955;5:227-42.
[2] Vesic A. Analysis of ultimate loads of shallow foundations. Journal of the Soil Mechanics and Foundations Division, ASCE. 1973;99:45-73.

[3] Oloo SY, Fredlund DG, Gan JK-M. Bearing capacity of unpaved roads. Canadian Geotechnical Journal. 1997;34:398-407.

[4] Costa YD, Cintra JC, Zornberg JG. Influence of matric suction on the results of plate load tests performed on a lateritic soil deposit. Geotechnical Testing Journal. 2003;26:219-26.

[5] Xu Y. Bearing capacity of unsaturated expansive soils. Geotechnical and Geological Engineering. 2004;22:611-25.

[6] Jahanandish M, Habibagahi G, Veiskarami M. Bearing capacity factor, $\mathrm{N} \gamma$, for unsaturated soils by ZEL method. Acta Geotechnica. 2010;5:177-88.

[7] Prandtl L. Über die Häerte plastischer Köerper. Nachrichten von der Gesellschaft der Wissenschaften zu Göttingen, Mathematisch-Physikalische Klasse. 1920;12:74-85.

[8] Reissner H. Zum erddruck problem. The 1st International Congress on Applied Mechanics. Delft1924. p. 295-311.

[9] Sokolovski WV. Statics of Soil Media. 2nd ed. London: Butterworths, 1954.

[10] Bishop AW. The principle of effective stress. Teknisk Ukeblad. 1959;106:859-63.

[11] Khalili N, Khabbaz MH. A unique relationship for chi for the determination of the shear strength of unsaturated soils. Géotechnique. 1998;48:681-7.

[12] Lu N, Griffiths DV. Profiles of steady-state suction stress in unsaturated soils. Journal of Geotechnical and Geoenvironmental Engineering. 2004;130:1063-76.

[13] Buckingham E. Studies on the movement of soil moisture. Bureau of Soils Bulletin 38. Washington, USA: U.S. Deparment of Agriculture, 1907.

[14] Richards LA. Capillary conduction of liquids through porous mediums. Physics. 1931;1:318.

[15] Gardner WR. Steady state solutions of the unsaturated moisture flow equation with application to evaporation from a water table. Soil Science. 1958;85:228-32.

[16] Davis EH, Booker JR. The bearing capacity of strip footings from the standpoint of plasticity theory. The 1st Australian New Zealand Conference in Geomechanics. Melbourne1971. p. 276-82.

[17] Martin CM. User guide for ABC - analysis of bearing capacity version 1.0. Oxford: University of Oxford, 2004.

[18] Martin CM. Exact bearing capacity calculation using the method of characteristics. In: Barla G, Barla M, editors. The 11th Conference of IACMAG. Turin, Italy2005. p. 441-50.

[19] Kumar J. The variation of $\mathrm{N} \gamma$ with footing roughness using the method of characteristics. International Journal for Numerical and Analytical Methods in Geomechanics. 2009;33:275-84.

[20] Davis EH, Booker JR. The effect of increasing strength with depth on the bearing capacity of clays. Géotechnique. 1973;23:551-63. 